\title{
Thulium laser to manage a difficult biliary lithiasis: a first case report
}

The thulium laser, a new therapeutic laser, has recently been introduced in the field of endoscopy to overcome the limitations of classic thermoablative therapies, particularly in terms of the precision of the technique and the risks associated with the procedure [1].

Although its main use is for hemostasis and ablation of lesions in the upper gastrointestinal tract, the thulium laser can be used in many other clinical situations [2]. In the present case, we report a new endoscopic application of the thulium laser, not yet described in the available international literature.

A 61-year-old woman presented to our center for a difficult lithiasis of the common bile duct associated with Mirizzi type II syndrome (cholecystocholedochal fistula). Two previous endoscopic treatments had been unsuccessful. The patient's past medical history included chronic ischemic heart disease, arterial hypertension, and severe obesity.

At cholangiography two biliary stones in the main bile duct were reported, the distal one located at the origin of the cystic duct. Several standard attempts to remove the stones using a 15-mm Fogarty biliary balloon (Cook Medical Inc., Bloomington, Indiana, USA) and a 7-Fr Dormia basket (Cook Medical) failed. Reviewing available literature on laser applications in endoscopy [1-3], we decided to use thulium laser lithotripsy (coagulation set-up: $20 \mathrm{~W}$ ablation/1 $\mathrm{W}$ coagulation, 365 micron fiber, 7 minutes application; Quanta System Srl., Milan, Italy) through SpyGlass cholangioscopy (Boston Scientific Corporation, Marlborough, Massachusetts, USA) ( $\vee$ Video 1 ). We decided to complete the lithotripsy using a mechanical lithotripter (Cook Medical) with

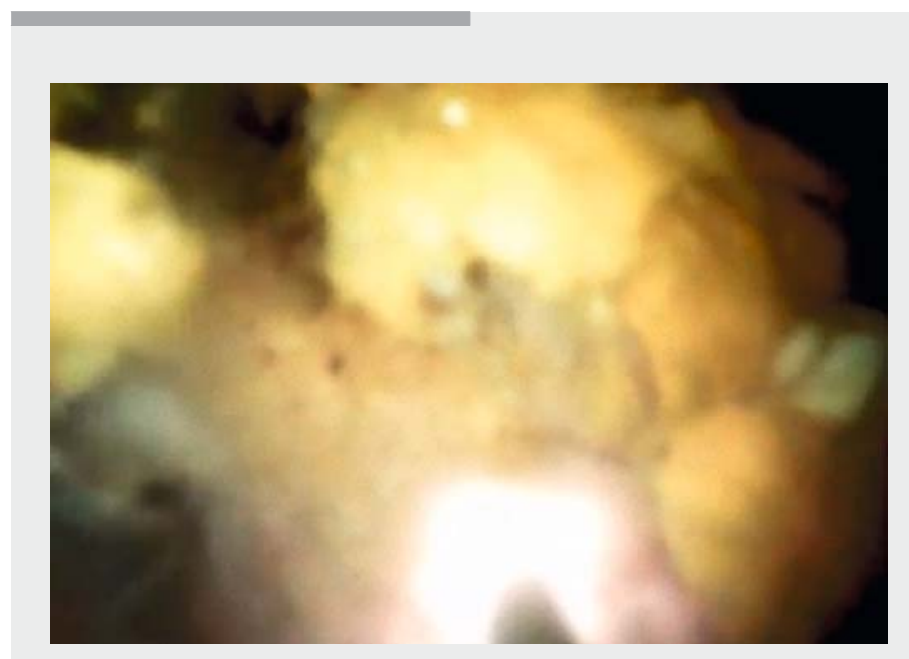

Video 1 Intrabiliary thulium laser lithotripsy conducted through a cholangioscopic guide to complete a difficult biliary lithiasis.

Dormia basket. Unfortunately, this strategy failed and the Dormia basket was blocked by the fragmented stones in the common bile duct. Lithotripsy was completed using a thulium laser to free the Dormia basket. As a precaution, we positioned a 7-Fr nasobiliary tube for 24 hours. No adverse events occurred and the patient was discharged after removal of the nasobiliary tube.

To our knowledge, this is the first case of biliary stone lithotripsy using a thulium laser. The technique seems to be safe, and faster and more effective than standard holmium laser lithotripsy [3].

Endoscopy_UCTN_Code_TTT_1AR_2AH

\section{Competing interests}

None
The authors

Massimiliano Mutignani, Lorenzo Dioscoridi, Angelo Italia, Edoardo Forti, Francesco Pugliese, Marcello Cintolo, Giulia Bonato, Aurora Giannetti, Mutaz Massad

Digestive and Interventional Endoscopy Unit, ASST Niguarda, Milan, Italy

Corresponding author

Lorenzo Dioscoridi, MD

Digestive and Interventional Endoscopy Unit, ASST Niguarda, Piazza Ospedale Maggiore 3, Milan, Italy

lorenzo.dioscoridi@ospedaleniguarda.it 
Bibliography

[1] Tontini GE, Neumann G, Pastorelli L et al. Thulium laser in interventional endoscopy: animal and human studies. Endoscopy 2017; 49: $365-370$

[2] Aldoukhi AH, Black KM, Ghani KR. Emerging laser techniques for the management of stones. Urol Clin North Am 2019; 46: 193 205

[3] Andreeva V, Vinarov A, Yaroslavsky l et al. Preclinical comparison of superpulse thulium fiber laser and a holmium:YAG laser for lithotripsy. World J Urol 2019. doi:10.1007/ s00345-019-02785-9
DOI https://doi.org/10.1055/a-0983-8278

Published online: 9.8.2019

Endoscopy 2020; 52: E112-E113

(c) Georg Thieme Verlag KG

Stuttgart · New York

ISSN 0013-726X

\section{ENDOSCOPY E-VIDEOS}

https:/|eref.thieme.de/e-videos

口回 Endoscopy E-Videos is a free 登视 靣: on interesting cases and new techniques in gastroenterological endoscopy. All papers include a high quality video and all contributions are freely accessible online.

This section has its own submission website at

https://mc.manuscriptcentral.com/e-videos 